there is a weak point, it concerns the "how." Several times the author mentions that academic librarians have severe problems in collective bargaining because of their minority position in the bargaining unit, but little comment is made as to how to solve this dilemma.

Similarly, the author admits that he offers no perspectives pro or con on how librarians should view collective bargaining in general. While librarians have long needed a dispassionate assessment of the collective bargaining movement and their place in it, in the case of this book, an objective and thorough treatment of the subject and some concrete concluding opinions from Weatherford, with his experiences, might have served a very useful purpose. Such minor considerations aside, however, this book is vital reading for all librarians contemplating unionization-or, simply, current issues in librarianship.-Lothar Spang, Assistant to the Director, Wayne State University Libraries, Detroit, Michigan.

Daniells, Lorna M. Business Information Sources. Berkeley: Univ. of California
Pr., 1976. 439p. \$14.95. LC 74-30517. ISBN 0-520-02946-1.

In the past decade in geometrically increasing numbers it seems businessmen have come to recognize the importance and necessity of up-to-date information in their problem solving and planning in all areas. Present curricula for business students require accessibility to a wider and wider range of information. There is more information around and in a greater variety of forms than ever before. Librarians must cope with these growths, and they need all the help they can get.

While there is a plethora of satisfactory, timely guides to specific aspects of business, there has not been a satisfactory general comprehensive guide to business sources since the second edition of Edwin T. Coman's Sources of Business Information in 1964. This new book by Lorna M. Daniells admirably meets the need. Businessmen, business students, and librarians will find it indispensable. She was asked to revise the earlier work; but with the great changes of the past ten years, while the

\title{
FOCUS ON ULORAPHICS
} from "The Authority"

\footnotetext{
Three recent issues of Library Reports now available separately:

The July 1976 issue includes an illustrated 28-page special report on library microform facilities with floor plans and photographs by Dr. Francis F. Spreitzer, and a survey of microform reader/printers. Also in this issue, a report on two micrographic cataloging data services, MarcFiche and Blackwell North America Title Index. - $\$ 40.00$. -

The September 1976 issue features an article on how to select a microfiche reader plus laboratory test reports on 9 microfiche readers including 7 of the newest dual and triple lens readers ... plus LTR's overall ratings of 21 microfiche readers previously tested by LTR. - $\$ 40.00$. -

The March 1977 issue contains laboratory test reports on 6 low-volume microfiche duplicators, ranging in price from $\$ 250$ to $\$ 2500$, and an introductory article on the selection and use of microfiche duplicators. $-\$ \mathbf{\$ 4 0 . 0 0}$.

Library Technology Reports (LTR) is a unique bimonthly publication of the American Library Association that provides critical evaluations of products used in libraries, media centers, schools, and other educational institutions. Its purpose is twofold: to enable librarians and educators to make economical decisions and to alert manufacturers of library needs and standards of performance expected.
} 
purpose of the book is much the same and some of the same material is covered, this is a completely different work.

Essentially a selected, annotated list of business books and reference sources emphasizing recent material in English and books published in the United States, the book is a distillation of experience of a business reference librarian at Baker $\mathrm{Li}$ brary at the Harvard Business School and reflects her expertise and personal assessments.

Roughly half of the book deals with basic sources: bibliographies, indexes and abstracts, directories, statistical and financial sources, and data on current trends. The latter half deals with specific management functions with handbooks and basic textbooks appearing first in each chapter followed by reference works. The concluding chapter lists a basic bookshelf.

The detailed index by author, title, and subject demonstrates further the growth and change of the past few years. There are three entries concerning automation in Coman's 1964 index and almost a full page of entries on computers in Daniells' 1976 index. It is to be hoped that plans are already underway for a new edition to come out a few years from now. One great value of this volume is its timeliness. A book with such timeliness and such broad coverage should also have some omissions and a few inaccuracies. These seem very hard to find. If I found any, I would let Ms. Daniells know for the next edition.-Barbara $R$. Healy, Management Library, University of Rochester, Rochester, New York.

Hicks, Warren B., and Tillin, Alma M. Managing Multimedia Libraries, New York: Bowker, 1977. 264p. \$13.95. LC 76-49116. ISBN 0-8352-0628-9.

Managing Multimedia Libraries is an important book. It might have been called Contemporary Library Management, for what library is there today which does not offer a multimedia approach? The title is, of course, related to Hicks and Tillin's earlier work, Developing Multimedia Libraries (Bowker, 1970), which became a vade mecum for many librarians who were expanding their information resources. In this new work, the authors have drawn upon their extensive knowledge of the multimedia environment (i.e., contemporary society); they relate their knowledge and experiences to the coordination of personnel management and to the planning and operating of processes in the modern library.

The work is comprehensive and carefully organized. Each chapter begins with an abstract of the topics to be treated in that chapter and concludes with a summary of the key points discussed. The bibliography is thorough, drawn from library literature, and provides both support for and further expansion of the topics treated. There is an appendix of sample job descriptions and an index.

The central concept of the book is the application of management by objectives in a systematic and humane fashion. The authors advocate a dynamic management approach which analyzes, structures, and evaluates the entire system, thereby allowing for and anticipating both change and progress within the organization. Hicks and Tillin demonstrate a broad acquaintance with management problems, both systembased and people-based. Short case studies and examples of practical applications are used to clarify and illuminate the principles of management responsibilities and techniques. These examples are real and relevant. The situations and the solutions are human and humanely discussed, treating elements such as "fairness" and "consideration" in the section dealing with personnel management.

The authors address library management as a systematic process, derived from sound and tested principles of management theory. Hicks and Tillin claim that "by using basic systems procedures and supplying data and detail specific to libraries, the translation of management skills into an effective and comprehensive methodology of library planning and development functioning can be achieved." And in this wellwritten monograph, they lay a blueprint for implementation of the process which they describe.

This new work should be required reading for professional librarians, regardless of the level of their role in management. Those who are being "managed" need to be familiar with the basic ground rules 